\title{
AUDICIÓN, IMAGEN, MEMORIA
}

\author{
Pilar Camacho Sánchez. \\ Universidad de La Rioja
}

\begin{abstract}
RESUMEN: Los análisis de la experiencia realizada demuestran que los alumnos son capaces de interesarse, investigar y recuperar el pasado y presente musical desde la propia sociedad de consumo actual. Utilizando como herramienta de trabajo un elemento familiar y cercano: los medios de comunicación de masas. En el diseño experimental de dicho trabajo interviene el componente lúdico-creativo como elemento motivador y evaluador. El análisis de los resultados obtenidos indica que este tipo de experiencias prácticas en las que se parte de algo conocido y cercano como la televisión, cine, publicidad... para alcanzar un fin creativo es capaz de contribuir al aprendizaje significativo en dinámica elemental más que otros medios tradicionales, e independientemente del Sistema Educativo del momento actual en España.
\end{abstract}

ABSTRACT: The analysis of the experience which I am writing about in this article shows that Secondary Education students can be really interested and search the musical past and present. I mean it even though many people and many teachers.

We can achieve that interest and good performance by the students using something familiar and close to them as a working tool. In this case I used the "mass media ". In the framework of this experimental project the playful and creative components constitute a very important motivating element.

The analysis of the results indicates that this kind of practical experiences wich are based on something previously well known to the students and which is a part of their daily reality; let's say "television, films, advertising " ... etc. Can have a high educational value. And I also think that they can also be much more meaningful in a school context than other traditional musical activities and experiences which are often carried out at school in the teaching of music.

\section{Introducción}

Durante varios años de docencia siempre he detectado en los alumnos cierto miedo y dificultad ante la audición musical - de lo que los entendidos Ilaman Grandes obras musicales; no digamos ante el estudio de una historia más: la Historia de la Música y sus compositores. El miedo y la inseguridad viene provocada por el temor a no reconocer la obra, a no saber qué escuchar y al desconocimiento de la historia de la música. En definitiva, ese miedo está causado por la falta de una cultura musical organizada, razonada y motivada desde la perspectiva actual del alumno. Este hecho, en parte, está justificado porque la música es un arte sobre todo temporal. Desde el mismo momento de su nacimiento o escucha se inicia su pérdida o ausencia, lo cual 
provoca serios problemas de retención o memorización de la obra musical.Este hecho, en las artes plásticas, es diferente; la obra de arte tiene un color, una forma, un tamaño... al igual que en la música, pero la obra se ve, permanece inalterada durante los años, se recuerda una imagen, aunque no un autor. Por este motivo experimenté con la música en la imagen como refuerzo para potenciar la audición y como estrategia para introducirnos en la historia de la música. El poder de una imagen en un medio de comunicación como la televisión -que además presenta una función e induce al consumo y que presenta una música-, hace que, se acumule inconscientemente en la memoria del individuo, y que éste sea capaz de memorizar y reconocer la música, aunque responda a motivos de consumo y no culturales.En definitiva, es utilizar un medio cercano para alcanzar un fin: conocer y fomentar la cultura musical de manera crítica y significativa.

La experiencia fue realizada con alumnos integrados en diferentes Sistemas Educativos, $3^{\circ}$ de BUP en el curso 1994-95 y de $2^{\circ}$ de Bachillerato en el curso 199697, pertenecientes a un mismo Centro de Secundaria en Logroño, IES TOMÁS MINGOT. Los resultados de las experiencias fueron parecidos a pesar del tiempo transcurrido y el año de diferencia en edad.

\section{Planteamiento: Unas cuantas cuestiones}

¿Cuáles podemos considerar que son las grandes obras de la música? ¿Las más escuchadas? ¿Las más vendidas? ¿las que perduran en la memoria colectiva a través del tiempo? ¿las que los "entendidos" consideran obras maestras? o quizás ¿aquellas que en su momento fueron las más innovadoras y creativas aunque fueran pocos los que las pudieron escuchar y entender?

Debemos preguntarnos también cuáles son los factores que provocan que un tema musical sea rápidamente reconocido por quien lo escucha. ¿La publicidad? ¿los medios de comunicación y los audiovisuales? ¿el nombre del autor? ¿la excelente calidad de la obra? ¿la casualidad y el azar?, o quizás ¿el entorno familiar junto al televisor?...

La realidad es que, por un motivo u otro hay una serie de obras, fragmentos, y sintonías musicales -de los que normalmente nadie tiene ni la más remota idea de cuál es su título y menos aún su compositor- que suenan a una mayoría de personas y que provocan parecidas expresiones: ¡Ay! ... sí,sí,... me suena, me suena...!

Imaginemos por un momento que estamos viendo una exposición que recoge las obras más relevantes de la pintura española. Y alguien al contemplar el cuadro "El Guernica" de Picasso diga: "creo que esta pintura la he visto antes.Sí,si, me parece que ya se de quién es: Velázquez".

Es poco probable, ¿no?... hasta puede parecer exagerado. Seguro que sí, en el campo de las artes plásticas. Pero en la música la realidad puede ser más grave. En el primer caso, únicamente se ha confundido épocas y pintores. En cambio, en el ámbito musical es fácil oír respuestas de este tipo:

- Es la del coche de marca... ( M.Caballé y F.Mercury ).

- La del limpiador de W.C... R.Wagner, La Valkiria ).

- La del perfume... (Bizet, Carmen). 
- La de las sopas... (A.Ponchielli , Danza de las horas).

- La de las letras del tesoro... (Beethoven. 9a . Sinfonía).

- La de los lavaplatos... (M.Ravel, El Bolero).

- La de Eurovisión...

(M. Charpentier, Te deum).

- La de las bodas...

(F.Mendelssohn, R.Wagner, La Marcha Nupcial).

- La de los dibujos animados: "Erase una vez...".

La de la película del perro; "Beethoven".

(Beethoven ,Septimino, op.20. Minuetto ).

- La de la película

(Beethoven, $5^{\underline{a}}$ sinfonía, adaptación Chuck Berry).

"Memorias de Africa" (Mozart, Concierto clarinete).

La confusión es, pues, en muchos casos, más exagerada. No sólo se confunde el compositor o el título y se sitúa la obra en otra época, sino que se relaciona únicamente con el uso que se le ha dado - publicidad, banda sonora, sintonía - ignorando por completo su origen o procedencia. No podemos evitar la comparación entre el compositor mucho, poco o nada conocido, y aquellos otros que quedarán en el anonimato y de los que sólo se conocerá su obra en relación al producto anunciado.

Ser recordado como marca de lavaplatos, colonias para Navidad o marca de sopas debe considerado culturalmente triste y musicalmente pobre.

\section{Objetivos en el aula.}

- El objetivo conceptual de la experiencia era conseguir que el alumnado fuera capaz de reconocer auditivamente una serie de obras musicales identificando rápidamente su autor y su título, y a continuación la época, el estilo, la textura, principales instrumentos, la forma musical.

- El objetivo procedimental de la experiencia era conseguir que el alumnado fuera capaz de seleccionar -esas músicas conocidas por todos, pero no identificadasde los medios de comunicación de masas, para posteriormente reconocer a sus autores y sus épocas a través de un elemento lúdico -El Concurso Musical- y finalmente crear un producto audio-visual.

- El objetivo actitudinal de la experiencia era conseguir que el alumnado fuera capaz de diferenciar las funciones y papeles adoptados por la música en los diferentes medios de comunicación de masas.Para ello había que desarrollar un sentido crítico ante el consumismo en la sociedad.

Se trata, pues, de demostrar que los docentes podemos aprovechar la habilidad adquirida por el alumno a través de los medios de comunicación y enfocarla hacia un sentido cultural, ya que es obvio y demostrable que los alumnos pueden memorizar con una facilidad extraordinaria una serie de obras musicales asociándolas, a la función publicitaria, imagen o producto determinado. Es decir, debemos trabajar con el alumno partiendo de este material familiar y conseguir que sea capaz de reconocer, identificar, memorizar y analizar toda una serie de obras musicales. Así, el trabajo que posteriormente realicemos en el área de música, en relación con las épocas o con estilos musicales, será más sencillo porque los alumnos dispondrán de unos esquemas mentales de referencia que les facilitará el aprendizaje significativo. 
Así mismo, esta experiencia permite dotar a los alumnos de una cultura musical general que les haga capaces de reconocer temas musicales, lo que parece importante y necesario para evitar tópicos como los que ya hemos comentado antes.

\section{Fases en el proceso experimental.}

La experiencia era bastante ambiciosa, pero el tema en cuestión es lo bastante amplio y atractivo como para que, girando sobre estas grandes obras musicales y sus imágenes publicitarias, pudiéramos trabajar todos aquellos contenidos que nos interesen:

- Conocimiento de instrumentos y voces.

- Agrupaciones instrumentales.

- Interpretación de partituras con instrumentos y de partituras con la voz.

- Evolución histórica y social de la música.

- Reconocimiento de formas y de texturas.

- Lenguaje musical convencional y alternativo.

- Las funciones de la música en los diferentes medios de comunicación de masas.

- Vivenciación del poder comunicativo que tiene una imagen, un texto y una música.

- Elaboración y creación de materiales Audio-visuales.

Los procedimientos llevados a cabo en el aula para el desarrollo de esta Unidad Didáctica se describen a continuación :

\section{P.Presentación y percepción del material audio-visual.}

El profesor presenta e introduce la Unidad Didáctica, con un breve explicación y con la visión de un vídeo sobre la música en la publicidad realizado por el Orfeón Donostiarra.

\section{$2^{\circ}$. Reconocimiento auditivo-visual de las obras musicales.}

Trabajamos la audición a través de la escucha de un C.D con grabaciones de anuncios publicitarios, músicas de series televisivas y bandas sonoras de películas conocidas. En una segunda audición introducimos la imagen de vídeo y el audio.

\section{$3 \%$. Selección de los temas musicales.}

La selección de obras se realizó teniendo en cuenta que tenían que ser conocidas, es decir, que "sonasen". Existen tantas que lo que en un principio se creyó muy sencillo no lo fue tanto, ya que muchas obras que para la profesora eran muy evidentes, el alumnado no las había oído nunca. Y viceversa.

Inicialmente la selección se concretó en 50 obras musicales que van desde el Ars Antiqua hasta el Siglo $X X$ abarcando diferentes estilos y géneros musicales -música culta, rock, pop, jazz, bandas sonoras originales y anuncios publicitarios-. El desnivel en la selección de temas musicales era tan evidente que se tuvo que ajustar de manera más equitativa y se determinaron finalmente cuatro grandes bloques musicales según su función o género musical y sobre todo en función del objetivo de dicha experiencia.

- La música de anuncios publicitarios. - La música de bandas sonoras originales.

- La música de series televisivas. - La música histórica. 
Todas ellas fueron consideradas y clasificadas como Las Grandes Obras Musicales.

Cuadro 1. Selección de obras.

\begin{tabular}{|c|c|c|c|}
\hline $\begin{array}{l}\text { Núm. } \\
\text { CD. }\end{array}$ & COMPOSITOR & TÍTULO & RECORDATORIO \\
\hline 1 & ANÓNIMO. (IX-XI) & Gregoriano & Bombones. Iglesia. Paz. Gusto. \\
\hline 2 & A. CHARPENTIER. 1643-1704. & Te Deum. & Conexión de Eurovisión. \\
\hline 3 & J.PACHELBEL. 1663-1706. & Canon y Giga. & Enorme canon. Intemporal. \\
\hline 4 & J.S.BACH. 1685-1750. & Toccata y fuga en re $\mathrm{m}$. & Familia Adams. Misterio. \\
\hline 5 & J.S.BACH. 1685-1750. & Concierto de Brandenburgo.n-3. Allegro. & Turno de oficio. Alegre. \\
\hline 6 & J.S.BACH. 1685-1750. & Magnificat. & Semanario. Espiritual. \\
\hline 7 & F.HAENDEL. 1685-1759. & Oratorio, El Mesías; Alleluya. & Polvorones. Grandioso. \\
\hline 8 & A.VIVALDI. 1678-1741. & Las cuatro estaciones: La Primavera. & Rondó. Descriptivo. \\
\hline 9 & L.BOCHERINI. 1743-1805. & Minuetto. & Miel. Muy dulce. \\
\hline 10 & W.A.MOZART. 1756-1791. & La flauta mágica. Aria Papageno. & Deportes. Divertida. \\
\hline 11 & W.A.MOZART. 1756-1791. & La flauta mágica. La reina de la noche. & Muy aguda. Es humana. \\
\hline 12 & W.A.MOZART. 1756-1791. & Pequeña serenata nocturna. no.1.Allegro. & Sintonía de programa. \\
\hline 13 & W.A.MOZART. 1756-1791. & Concierto para clarinete.KV 622.Adagio. & Memorias de Africa. \\
\hline 14 & L.V.BEETHOVEN. 1770-1827. & Sonata: El claro de luna. & Colonia. Romanticona. \\
\hline 15 & L.V.BEETHOVEN. 1770-1827. & Sinfonía nº . 9ª. & Letras del tesoro. Libertad. \\
\hline 16 & L.V.BEETHOVEN. 1770-1827. & Septimino,op.20. Minuetto. & Érase una vez... Dibujos. \\
\hline 17 & L.V.BEETHOVEN. 1770-1827. & Sinfonía $\mathrm{n}^{0} .5$ & Beethoven. El perro. El destino. \\
\hline 18 & J. STRAUSS I. 1804-1849. & Polca-Pizzicato. & Polca. Rondó. Original cuerda.. \\
\hline 19 & J. STRAUSS I. 1804-1849. & Marcha Radetzky. & Concierto fin de año. \\
\hline 20 & F.MENDELSSOHN. 1809-1847. & Marcha Nupcial. & Bodas. Antes de... \\
\hline 21 & R.WAGNER. 1813- 1883. & Marcha Nupcial. & Bodas. Después de casarse. \\
\hline 22 & R.WAGNER. 1813- 1883. & La Walkiria.Cabalgata de las walkirias. & Apocalipsis now. Desinfectante. \\
\hline 23 & G.VERDI. 1813-1901. & Nabuco. Va, penseiro, sull'ali dorate. & Coro de ópera. Agradable. \\
\hline 24 & G.VERDI. 1813-1901. & La traviata. El brindis. & Champán. J.Carreras. \\
\hline 25 & J.STRAUSS II. 1825-1899. & El Danubio azul. & Vals por excelencia. Sisí. \\
\hline 26 & J. BRAHMS. 1833-1897. & Danzas húngaras nº.5. & Rebajas. Sabor a ruso. \\
\hline 27 & A. PONCHIELLI. 1834-1886. & Danza de las horas. & Sopas knorr. Insinuación. \\
\hline 28 & BORODÍN. 1834-1887. & Danzas Polotvsianas. & Cerveza. \\
\hline 29 & G.BIZET. 1838-1875. & Carmen.Suite $\mathrm{n}^{\circ} .2$ & Perfume. Habanera. \\
\hline 30 & P.TCHAIKOVSKI. 1840-1893. & La bella durmiente. Vals. & Principe azul. Martes y Trece. \\
\hline 31 & A. DVORAK. 1841- 1904. & Sinfonía nuevo mundo. $2^{\circ}$ movimiento. & Perro Pippin. Abandono. \\
\hline 32 & R. KORSAKOV. 1844-1908. & Vuelo del moscardón. & Graciosa: sssss, sssss. \\
\hline 33 & TÁRREGA. 1852-1909. & Recuerdo de la Alhambra de Granada. & Salchichas. Andalucía. \\
\hline 34 & C.DEBUSSY. 1862-1918. & Claro de luna. & 7 días en el Tibet. Bratt Pet. \\
\hline 35 & M. RAVEL. 1875-1937. & El Bolero. & Lavabajillas. Cansado. \\
\hline 36 & R.STRAUSS. 1864-1949. & Así habló Zaratrusta. & Conocido desde 2001. \\
\hline 37 & TURINA. 1882-1942. & Danzas fantásticas. & Brandy. Muy español. \\
\hline 38 & S. PROKOFIEV. 1891-1953. & Pedro y el lobo. & Cuento de instrumentos. \\
\hline 39 & C.ORFF. 1895-1982. & Carmina burana. Oh, fortuna. & Excalibur. Lubricante. Impactante. \\
\hline 40 & G. GERSHWIN. 1898-1937. & Rhapsody in blue. & Es Jazz. \\
\hline 41 & A.KHACHATURIAN. 1903-1978 & Danza del sable. & Divertida. Rápida. \\
\hline 42 & G. MILLER. 1904-1944. & En forma. & Winston. Pegajosa. \\
\hline 43 & STEVE MILLER. & The joker. & Cerveza. Buena. \\
\hline 44 & B. MCFERRIN. & Don't worry, be happy. & Compresa. Empezar el día. \\
\hline 45 & J. WILLIAMS. & BSO Superman. & Un banco. Cómic. \\
\hline 46 & L. BERNSTEIN. 1918-1990. & West side history: América. & Ópera moderna. Historia de amor. \\
\hline 47 & BILL HALEY. 1925-1981. & Rock around the clock. & El origen del rock. \\
\hline 48 & J. LENNON. & Imagy. & Coche. Beatles. Un cambio... \\
\hline 49 & H. MANCINI & La pantera rosa. & Dibujos animados. \\
\hline 50 & J. COCKER. & You can leave your hat on. & El termómetro sube. Nueve...y media \\
\hline
\end{tabular}




\section{4º . Cómo recordar las obras. Estrategia metodológica.}

Cada tema musical se escuchaba en clase, presentándolo dentro del espacio reservado a las grandes obras de la música y dejando que fueran los alumnos los que intentaran descubrir cómo se titulaba, quién la había compuesto, de qué la conocían o dónde la habían escuchado antes.

Normalmente los fragmentos musicales propuestos eran rápidamente reconocidos pero no siempre acertados. Incluso, siempre que se podía, se comentaban datos, anécdotas sobre el autor y la obra y después se elaboraba el trabajo específico de acuerdo con el tema musical propuesto. [ Cuadro 2].

\section{Cuadro 2. Fichas personales.}

Autor: J.STRAUSS. I.

Obra: Polca - Pizzicato.

Época: Romanticismo/ Nacionalismo.

Características: El tratamiento de los instrumentos de cuerda frotada: "Pizzicato".

Forma rondó: ABACA...

Juego de intensidades y cambios de tempi.

Recordatorio: Alegre, graciosa y divertida. Me suena de algunos dibujos animados.

Valoración: 7. Me ha gustado bastante

Autor: L.V.BEETHOVEN.

MARÍA

Obra: Septimino en Mi bemol. Op.20. Minuetto.

Época: Clasicismo / Romanticismo.

Características: Siete instrumentos: Violín, viola, violoncello, contrabajo, clarinete, fagot y trompa. Forma de Lied: ABA.

Recordatorio: Alegre y divertida. "Érase una vez el hombre", serie de dibujos animados. No sabía que fuera de Beethoven. ( El texto es añadido).

Valoración: 6. Está bien, pero otras me gustan más.

Autor: R.WAGNER.

RAÚL

Obra: La Walkiria. "Cabalgata de las Walkirias".

Época: Nacionalismo Alemán. Ópera.

Características: Tratamiento orquestal de la masa sonora. Arte total, prepara algo más grandioso.

Nuevas sonoridades y combinación de instrumentos.

Parte de una ópera. Género dramático.

Colocación de los instrumentos en la partitura.

Recordatorio: Es grandiosa, llena todo el espacio sonoro. No sabía que se había utilizado en varios anuncios publicitarios tan diferentes. Conocía el tema por la película de "Apocalipsis now".

Valoración: 9. Tiene fuerza. Es una pasada. Me gusta mucho.

Los alumnos tenían que elaborar unas fichas de todas las obras musicales en su cuaderno de la siguiente manera:

- Título, autor, época, estilo: Apartado que fue explicado y comentado por la profesora. Es lo que se les pediría saber al escuchar uno de los temas musicales.

- Características musicales: Cuál es el motivo del trabajo del fragmento musical escuchado y destacar los elementos musicales como el ritmo, melodía, carácter, tempo, textura, forma, agrupaciones tímbricas. 
- Comentario: Deben brevemente explicar que impresión les ha causado, qué sentimiento o reacción les produce o bien de qué la conocen. (Medios de Comunicación )

- Valoración personal: Calificar numéricamente de 0 a 10 cuantificando en qué grado ha gustado individualmente.

Lo importante era que a partir de este trabajo el alumnado fuese capaz de relacionar estos fragmentos musicales con su título y autor. Para ello, utilizaba alguno de los elementos comentados en el aula. Logrando estudiar las obras sin necesidad de escucharlas, ya que un tanto por ciento muy elevado las recordaba a partir de su comentario, características musicales o valoración personal. [ Cuadro 3].

Cuadro 3. Relación de obras musicales y trabajos en el aula

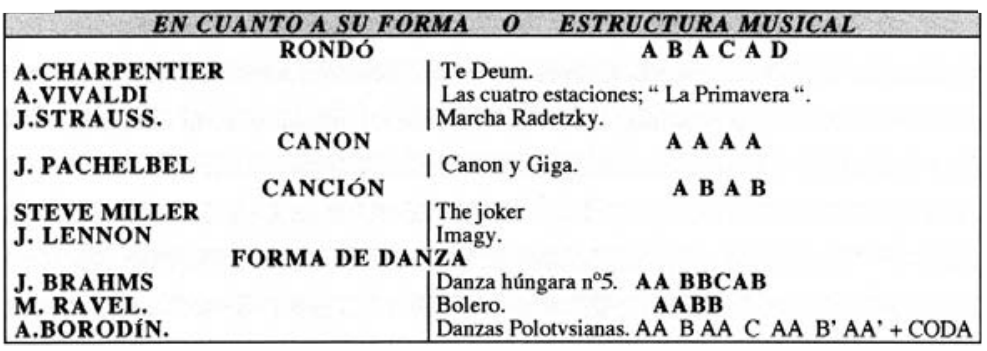

\begin{tabular}{|c|c|}
\hline \multicolumn{2}{|c|}{ NOTACIONN - PARTITURA } \\
\hline $\begin{array}{l}\text { Anónimo. Gregoriano. } \\
\text { PACHELBEL. } \\
\text { W.A.MOZART. } \\
\text { BEETHOVEN }\end{array}$ & $\begin{array}{l}\text { Puer natus est. } \\
\text { Canon. } \\
\text { Pequeña serenata nocturna. } \\
\text { Sinfonía } \mathrm{n}^{\circ} 9 .\end{array}$ \\
\hline
\end{tabular}

\begin{tabular}{|l|l|l|}
\hline \multicolumn{3}{|c|}{ INSTRUMENTOS } \\
\hline BACH & Tocatta y fuga en re m. & Organo. \\
VIVALDI & La Primavera. & Clavicémbalo. \\
BEETHOVEN. & Claro de luna & Piano. \\
G.MILLER. & En forma. & Saxofones. \\
BEETHOVEN & Septimino. & Cuarteto de cuerda y clarinete, fagot, trompa. \\
PROKOFIEV & Cuarteto cuerdas, flauta, oboe, fagot, clarinetes, \\
\hline
\end{tabular}

\begin{tabular}{|l|l|}
\hline \multicolumn{2}{|c|}{$V O Z}$. \\
\hline MOZART & La reina de la noche. \\
BEETHOVEN & Sinfonía 9 \\
VERDI & Coro.Nabuco.Va penseiro... \\
ORFF & Oh Fortuna. \\
COCKER & You can leave your hat on. \\
MCFERRIN & Don't worry, be happy. \\
BERNSTEIN & West side history. \\
\hline
\end{tabular}

\begin{tabular}{|l|l|l|}
\hline \multicolumn{3}{|c|}{ TEXTURAS MUSICALBS } \\
\hline GREGORIANO & Monodía a capella. & Puer Natus est. \\
MOZART & Melodía acompañada. & Aria de la reina de la noche. \\
VIVALDI & Homofónica. & La primavera. \\
BACH & Contrapuntística. & Concierto de Brandenburgo \\
HAENDEL & Mixta. & EL Mesías. Aleluya. \\
\hline
\end{tabular}

\begin{tabular}{|l|l|}
\hline \multicolumn{2}{|c|}{ AGRUPACIONES OROUESTALES. } \\
\hline J.S.BACH & Concierto de Brandenburgo. \\
HANDEL & El mesías. \\
BEETHOVEN & Sinfonía n ${ }^{\circ}$. \\
R.STRAUSS & Así habló Zaratrusta. \\
KHACHATURIAN & La danza del sable. \\
M.RAVEL & El bolero. \\
G.GERHWIN & Rhapsody in blue. \\
H MANCINI. & La pantera rosa. \\
J.WILLIAMS & Superman \\
\hline
\end{tabular}




\section{5‥ El carácter lúdico: Motivación y autoevaluación.}

En el momento en que cada grupo había escuchado e identificado seis o siete obras, se introdujo el componente lúdico con un fin motivador y evaluador del proceso de enseñanza-aprendizaje de la profesora y del alumnado. Así, empezó el juego de adivinar y relacionar cada obra con su autor y título. Aprovechando que los concursos televisivos están tan de moda en nuestra sociedad, fue fácil y de gran aceptación la introducción del Concurso Musical en el aula.

El debate vino después cuando tuvimos que dar un nombre al concurso. Entre los diversos títulos propuestos señalaremos los siguientes: "Oigo, Oigo...¿Qué escuchas?", "Adivina quién suena", "La música tiene dueño", "En clave de sol" o "Toma nota"... En definitiva sólo era el título de un juego y los alumnos sabían que estaban trabajando con algo mucho más importante: las grandes obras de la música.

Para concursar, la clase se organizaba en seis equipos de cuatro o cinco miembros cada uno, distribuidos espacialmente de manera diferente a la habitual en el aula. Cada grupo asignaba un portavoz y tenía que escoger un número que correspondía a un CD de una de las obras. Después de colocar el disco en el aparato reproductor, era necesario escuchar un breve fragmento y contestar correctamente en un tiempo determinado. Si fallaban, había rebote y la pregunta pasaba a otro grupo. Los puntos del juego se escribían en la pizarra.

El concurso es sencillo pero el solo hecho de jugar con el azar, la incertidumbre sobre qué obra les tocaría y la tensión de quién contestaría las tres Superpreguntas, que suponía el doble o la mitad en la puntuación final, motivaba a los alumnos para aprender a relacionar exactamente a quién correspondía cada fragmento musical y qué título tenía. La Superpregunta consiguió aumentar la atención en el momento de trabajar aspectos musicales, ya que sabían que esto les ayudaría a entender mejor la música, a reconocer los temas propuestos y a doblar la puntuación final en el concurso musical.

\section{6‥ Que empiece el espectáculo.}

Finalmente, esta experiencia en el aula alcanza el momento más reflexivo, maduro, crítico, práctico e imaginativo en el proceso del aprendizaje significativo. Se trata de la creación, montaje, interpretación, producción y estreno mundial de un producto audio-visual. Es el momento de su propia autoevaluación, mostrando al público la creación de sus propias conocimientos, reconociendo los mensajes que pueden llegar a transmitir, elaborados por los propios alumnos en grupos de 6 a 10 componentes.

Dónde se complementan al menos dos artes, una común que es la música y las otras variables, como la imagen, la poesía, la danza. Todas ellas tendrían el mismo denominador común; LA EDUCACIÓN PARA EL CONSUMO, como Eje Transversal .

Las producciones realizadas se clasificaron en varios grupos:

- Diaporamas. (Música y diapositivas. Música, diapositivas y texto).

- Videoclips- musicales. (Música, teatro).

- Spots publicitarios. (Música, producto).

- Cuentos musicales. (Dramatización con música).

- Coreografías y danzas. (Música y expresión corporal). 
Debo de comentar que la calidad de las producciones realizadas no fue la deseada, pero sí fue superior a los medios disponibles en el aula; sin embargo, me siento en la obligación de señalar que el mensaje subliminal de la mayoría de las producciones fue más que positivo, gratamente satisfactorio y sorprendente.

\section{Conclusiones}

Se constató que los alumnos que habían realizado esta Unidad Didáctica tenían más facilidad en el momento de:

- Entender y conocer en general la evolución de la música a través del tiempo, encuadrándola dentro de unas determinadas épocas históricas.

- Conocer en concreto los cambios artísticos, socio-culturales y musicales que caracterizan una época de otra.

- Discriminar auditivamente las características musicales atendiendo a: estilos de cada época, géneros, peculiaridades de cada compositor, reconocimiento de instrumentos y formas musicales.

- Apreciar y vivenciar el poder que tienen por sí solas y en conjunto la imagen, el texto y la música en cualquier proceso de comunicación de masas.

- Diferenciar objetivamente el papel y la función de la música en los diferentes medios de comunicación de masas: cine, televisión, publicidad.

- Realizar juicios personales y crítica de valores ante la manipulación que ejercen los mass-media en la sociedad de consumo.

- Valorar y respetar los diferentes trabajos relacionados con los medios de comunicación de masas.

Por último, destacar que la Unidad Didáctica se temporalizó en cuatro meses, de octubre a febrero, con cuatro sesiones semanales. Los objetivos programados se cumplieron satisfactoriamente. Es más, el clima relajado y de buen humor que se respiró durante todo el proceso, contribuyó al buen desarrollo del trabajo.

\section{Referencias Bibliográficas}

AMES, C; AMES, R. (1984). "Systems of student and teacher motivation. Toward a qualitative definition" en Journal of Educational Psychology, vol.76, ํo-4, pp. 535556.

COPLAND, A. (1955). Cómo escuchar la música . México. Fondo de cultura económica, 1981.

CHION, M. La música en el cine. Barcelona. Paidós.

FLANDERS, N.A. (1977). Análisis de la interacción didáctica. Madrid. Anaya.

FODOR, J. (1986). The modularity of Mind. Mit. Press. Morata. Madrid.

FREGA, A. L. (1997). Música para maestros. Barcelona. Graó.

GINESTÁ, A. (1997). "¡Ostras...,me suena,..me suena!.". En Eufonía, Didáctica de la música. Barcelona, n 8 , pp 101-106. 


\section{PILAR CAMACHO SÁNCHEZ}

GUILFORD, J. P. y otros (1983). Creatividad y educación.. Buenos Aires. Paidós.

RIERA, C. y otros. (1994). Audición 1. Forma y color en la música.. Barcelona. Dinsic.

SAVATER, F. (1987). El valor de educar. Barcelona. Ariel.

STEFANI, G. (1987). Comprender la música.. Barcelona. Paidós.

XALABARDER, C. Enciclopedia de las bandas sonoras. Edit. Grupo Zeta.

ZABALA, A. (1995). Cómo trabajar los contenidos procedimentales en el aula.. Barcelona. Graó / ICE de la UB. 